\title{
ZONASI DAN STATUS KAWASAN EKOSISTEM LAGUNA DI NEGERI IHAMAHU, MALUKU TENGAH
}

\section{(Zonation and Status of Lagoon Ecosystem Area in Ihamahu Village, Central Maluku)}

\author{
Daniel G. Louhenapessy \\ Jurusan Budidaya Perairan \\ Fakultas Perikanan dan Ilmu Kelautan Universitas Pattimura \\ Jl.Mr.Chr.Soplanit, Poka-Ambon \\ d_louhen@yahoo.com
}

\begin{abstract}
ABSTRAK: Ekosistem laguna memiliki produktivitas yang tinggi dalam sektor perikanan. Masyarakat Negeri Ihamahu memanfaatkan sumberdaya pada ekosistem laguna untuk pemenuhan kebutuhan hidup. Tujuan penelitian ini adalah menganalisis peta zonasi dan status kawasan ekosistem laguna Negeri Ihamahu. Metode penelitian yang digunakan untuk menganalisis peta zonasi dan status kawasan yaitu dengan pendekatan SIG melalui teknik analisis spasial serta metode Focus Group Discussion (FGD). Hasil penelitian menunjukkan terdapat sembilan laguna dengan luasan yang berbeda. Berdasarkan hasil FGD diperoleh empat status kawasan ekosistem laguna Negeri Ihamahu yaitu kawasan konservasi, budidaya, penangkapan serta rehabilitasi. Penetapan zonasi dan status kawasan merupakan upaya pengelolaan ekosistem laguna secara berkelanjutan.
\end{abstract}

Kata Kunci: laguna, pengelolaan berkelanjutan, SIG, konservasi, rehabilitasi

ABSTRACT: Lagoon ecosystems have high productivity in the fisheries sector. Communities of Ihamahu village utilize resources in this ecosystem to meet their daily needs. The aim of this study was to analyze the zoning map and the status of the lagoon ecosystem of Ihamahu village. The research method used in this research was the Geogrpahic Information System with using spatial analysis techniques in collaboration with the Focus Group Discussion (FGD) method. The results revealed that there were nine lagoons with different areas. Four out of nine lagoons are used as conservation, aquaculture, fishing and rehabilitation sites. The establishment of the zonation and status of lagoon areas is a proper way to manage the lagoon ecosystem sustainably.

Keywords: lagoon, sustainability management, GIS, conservation, rahabilitation

\section{PENDAHULUAN}

Ekosistem pesisir memiliki potensi sumberdaya yang dapat dimanfaatkan bagi pemenuhan kebutuhan hidup manusia, salah satunya yaitu ekosistem laguna. Ekosistem laguna memiliki produktivitas yang tinggi khususnya sumberdaya perikanan (Anthony, et al., 2009). Laguna sebagai penyedia sumberdaya dan jasa ekosistem yang bukan hanya menjadi sumber mata pencaharian masyarakat namun juga memiliki banyak manfaat bagi kesehatan dan kesejahteraan masyarakat, sehingga laguna dapat dijadikan sistem sosial-ekologi yang kompleks bagi kehidupan di alam (Newton et al., 2014). Masyarakat Negeri Ihamahu sangat bergantung pada keberadaan ekosistem laguna tersebut. Sumberdaya yang dimanfaatkan antara lain teripang, penyu dan berbagai jenis ikan karang. 
Tingkat konsumsi ikan oleh masyarakat Negeri Ihamahu sangat tinggi, sehingga mengakibatkan tingginya pemanfaatan pada ekosistem laguna. Pola pemanfaatan yang dilakukan akan menimbulkan degradasi sumberdaya ekosistem laguna Negeri Ihamahu.

Tekanan ekologis pada ekosistem laguna terus terjadi bukan hanya pada pemanfaatan sumberdaya saja, namun juga diakibatkan oleh pembuangan sampah di wilayah pesisir yang nantinya terbawa ke laguna. Sampah plastik yang terurai berupa mikroplastik akan sangat mudah dikonsumsi oleh sumberdaya pada ekosistem laguna. Dampak yang ditimbulkan bagi biota yaitu akan mengalami gangguan pencernaan, sehingga menganggu metabolisme tubuh biota (Smith, et al., 2018). Dampak lainnya yaitu jika sumberdaya tersebut dikonsumsi oleh manusia melalui proses rantai makanan maka kandungan senyawa berbahaya pada mikroplastik akan terserap masuk ke dalam tubuh manusia. Secara visual, sampah di pesisir Negeri Ihamahu berasal dari pembuangan sampah masyarakat yang bermukim di daerah pantai. Telah banyak upaya yang dilakukan baik oleh Pemerintah Negeri Ihamahu maupun masyarakat untuk mengurangi sampah di pesisir melalui ajakan dan larangan berupa papan himbauan telah diletakan pada daerah pantai, serta aksi bersih yang dilakukan dengan membakar serta membuat lubang untuk menimbun sampah.

Selain itu, pertambahan penduduk yang semakin meningkat juga mengakibatkan penurunan sumberdaya pada ekosistem laguna, karena tingginya tingkat pemanfaatan yang terjadi. Berdasarkan data Badan Pusat Statistik (BPS) tahun 2018, jumlah penduduk Negeri Ihamahu meningkat dari 1.551 jiwa menjadi 1.627 jiwa di tahun 2017. Masyarakat cenderung hanya memanfaatkan sumberdaya pada ekosistem laguna untuk kebutuhan konsumsi dan ekonomi tanpa melihat keberlanjutan pada sumberdaya tersebut. Untuk itu perlu upaya yang ditempuh untuk mengendalikan terjadinya degradasi sumberdaya ekosistem laguna Negeri Ihamahu. Salah satunya yaitu mengatur tingkat pemanfaatan sumberdaya ekosistem laguna oleh masyarakat melalui pembuatan peta zonasi.
Berdasarkan Undang-Undang Nomor 27 tahun 2007 tentang Pengelolaan Wilayah Pesisir dan Pulau-Pulau Kecil, zonasi merupakan suatu bentuk rekayasa teknik pemanfaatan ruang melalui penetapan batas-batas fungsional sesuai dengan potensi sumber daya dan daya dukung serta proses-proses ekologis yang berlangsung sebagai satu kesatuan dalam ekosistem pesisir. Peta zonasi yang telah dihasilkan serta didukung dengan aturan tertulis dari pemerintah setempat akan menjadi pedoman yang harus diikuti oleh semua unsur di Negeri Ihamahu untuk melestarikan ekosistem laguna. Penelitian ini bertujuan untuk menganalisis peta zonasi dan status kawasan ekosistem laguna Negeri Ihamahu.

\section{METODE PENELITIAN}

Penelitian dilakukan pada bulan Mei Juni 2017 di Negeri Ihamahu, Kecamatan Saparua Timur Maluku Tengah (Gambar 1). Pengumpulan data primer dilakukan secara langsung pada ekosistem laguna Negeri Ihamahu secara insitu dan melalui kegiatan FGD (Focus Group Discussion). Sedangkan data sekunder meliputi data penelitian sebelumnya serta data kependudukan diperoleh melalui penelusuran pustaka. Analisa data dilakukan dengan pendekatan analisis spatial dengan menggunakan SIG (Sistem Informasi Geografis). Data berupa peta yang diperoleh dari hasil pemetaan partisipatif masyarakat diolah dengan menggunakan software ArcGis 10.3 dan kemudian divalidasi dan diverifikasi untuk menghasilkan peta zonasi serta penetapan status kawasan.

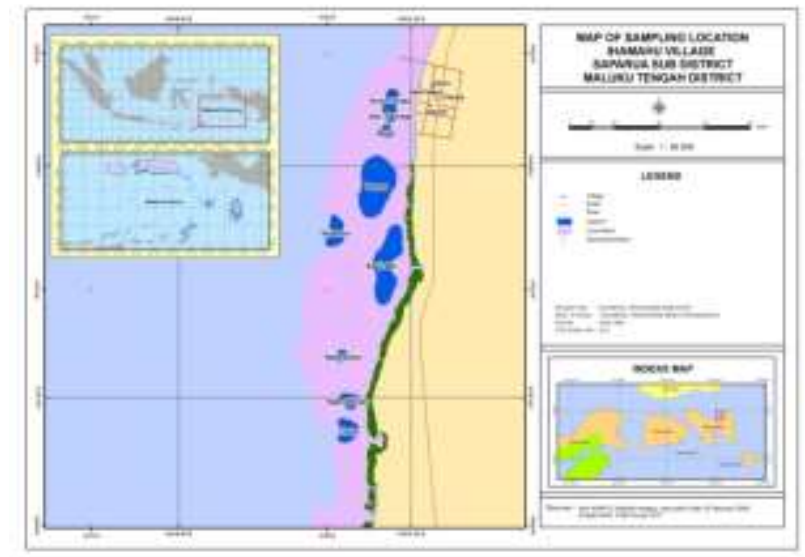

Gambar 1. Peta lokasi penelitian 


\section{HASIL DAN PEMBAHASAN}

Berdasarkan hasil penelitian terdapat sembilan laguna di Negeri Ihamahu yaitu Kolam Kusu-kusu, Kolam Aer Salobar, Kolam Ayau, Kolam Basar, Kolam Selaono, Kolam Kaki aer, Kolam Namalono, Kolam Namattiralo dan Kolam Hohu (Gambar 2). Masyarakat Negeri Ihamahu umumnya menggunakan istilah kolam pada setiap laguna. Sesuai dengan namanya, Kolam Basar memiliki luasan terbesar dibandingkan dengan kolam lainnya. Pada Kolam Basar ini tingkat pemanfaatan terhadap sumberdaya cukup tinggi. Menurut Siahainenia, $d k k$. (2017), teridentifikasi beberapa aktivitas yang dilakukan pada ekosistem laguna Negeri Ihamahu yaitu penangkapan ikan, bameti dan pembuangan sampah.

Masyarakat Negeri Ihamahu sangat gemar makan ikan sehingga aktivitas penangkapan ikan dilakukan setiap hari. Aktivitas penangkapan ikan paling banyak dilakukan pada Kolam Besar dengan menggunakan beberapa alat tangkap yaitu pancing, jaring dan redi. Seperti diketahui alat tangkap redi dikategorikan termasuk dalam alat tangkap tidak ramah lingkungan yang akan merusak ekosistem lainnya di perairan. Aktivitas pengambilan moluska yang disebut bameti dilakukan
DOI: $\underline{\text { https://doi.org/10.30598/TRITONvol15issue2page69-75 }}$

sebagian besar masyarakat untuk dikonsumsi sehari-hari dan tidak untuk dijual. Pemanfaatan wilayah pesisir lainnya yang berdampak negatif bagi keberadaan sumberdaya ekosistem laguna yaitu pembuangan sampah yang setiap hari dilakukan oleh masyarakat yang bermukim di wilayah pesisir Negeri Ihamahu. Sampah dapat terbawa arus dan terperangkap pada daerah terumbu karang khususnya hard coral (Richards and Beger, 2011). Keberadaan sampah akan mempengaruhi kesehatan karang terutama polip. Masyarakat memanfaatkan wilayah pantai Negeri Ihamahu untuk membuang sampah, khususunya masyarakat yang bermukim sangat dekat dengan pantai. Seperti diketahui, sampah baik organik maupun anorganik dapat menurunkan estetika pantai maupun mengganggu metabolisme biota perairan (Xanthos, D and Walker, 2017; Willis et al., 2018). Menurut informasi dari masyarakat, larangan membuang sampah telah diberitahukan kepada masyarakat oleh Pemerintah Negeri, namun kebiasaan tersebut belum dapat diubah. Kegiatan pembersihan pantai dari sampah sering dilakukan seperti pembakaran sampah kering dan pembuatan kolam di tepi pantai untuk menanam sampah karena sampah basah karena sulit dibakar.

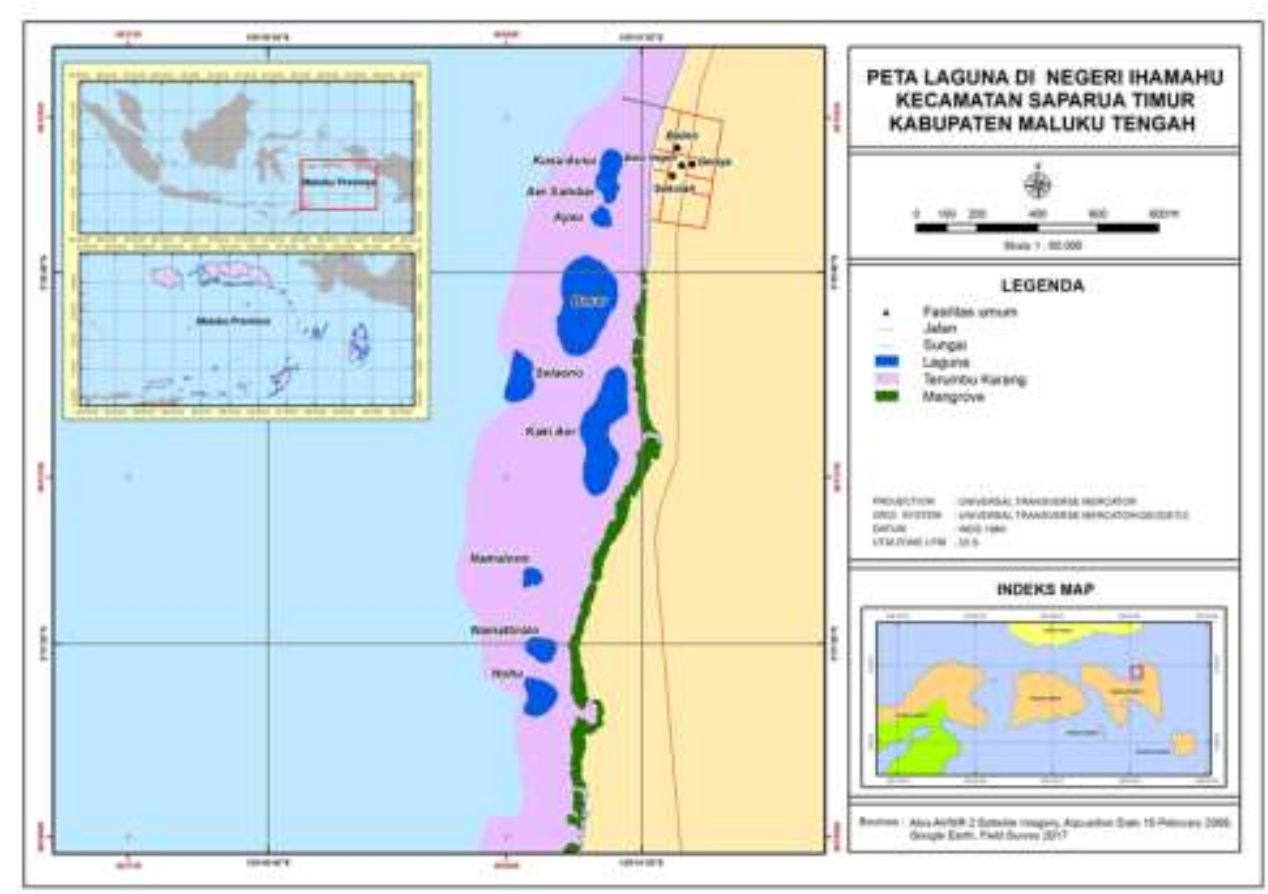

Gambar 2. Sembilan laguna di Negeri Ihamahu 
Kegiatan FGD yang dilakukan dihadiri oleh perwakilan pemerintah Negeri Ihamahu, kewang, tokoh adat, tokoh agama, pemuda serta nelayan. Berdasarkan hasil FGD diperoleh informasi bahwa masyarakat mengakui telah terjadi degradasi pada terumbu karang yang berada di Kolam Basar. Tingginya tingkat pemanfaatan oleh masyarakat dengan mengggunakan jaring redi cenderung merusak terumbu karang. Seperti diketahui, terumbu karang memiliki fungsi penting secara ekologi maupun ekonomi. Terumbu karang merupakan habitat berlindung, mencari makan, berkembang biak serta memijah berbagai jenis biota perairan. Secara ekonomi, terumbu karang dapat memberikan lapangan kerja serta memenuhi kebutuhan hidup sehari-hari khususnya pangan bagi masyarakat. Kerusakan terumbu karang akan berdampak bagi biota yang berasosiasi serta masyarakat sebagai pengguna sumberdaya. Ekonomi masyarakat Negeri Ihamahu sangat bergantung pada sumberdaya pesisir dan lautan selain pada sumberdaya daratan. Menurut Siahainenia, dkk. (2018) menyatakan bahwa persepsi masyarakat Negeri Ihamahu terhadap pemanfaatan sumberdaya ekosistem laguna dari aspek ekonomi berada dalam kategori positif. Artinya bahwa pemanfaatan sumberdaya pada ekosistem laguna dapat meningkatkan perekonomian masyarakat Negeri Ihamahu.

Telah banyak aturan tertulis maupun tidak tertulis yang dikeluarkan oleh pemerintah Negeri Ihamahu, namun belum dipatuhi oleh masyarakat. Dengan demikian maka diperlukan suatu penegasan aturan yang bertujuan untuk mengurangi tekanan ekologis terhadap sumberdaya ekosistem laguna. Salah satunya melalui penetapan peta zonasi dan status kawasan perairan ekosistem laguna Negeri Ihamahu sesuai dengan kondisi sumberdaya perairan di ekosistem tersebut. Berdasarkan hasil penelitian diperoleh ekosistem laguna Negeri Ihamahu diklasifikasikan menjadi kawasan konservasi, kawasan rehabilitasi, kawasan budidaya dan kawasan penangkapan (Gambar 3). Berdasarkan Undang-Undang Nomor 27 tahun 2007 tentang Pengelolaan Wilayah Pesisir dan Pulau-Pulau Kecil, konservasi wilayah pesisi dan pulau-pulau kecil adalah upaya perlindungan, pelestarian, dan pemanfaatan wilayah pesisir dan pulau-pulau kecil serta ekosistemnya untuk menjamin keberadaan, ketersediaan, dan kesinambungan sumberdaya pesisir dan pulau-pulau kecil dengan tetap memelihara dan meningkatkan kualitas nilai dan keanekaragamannya.

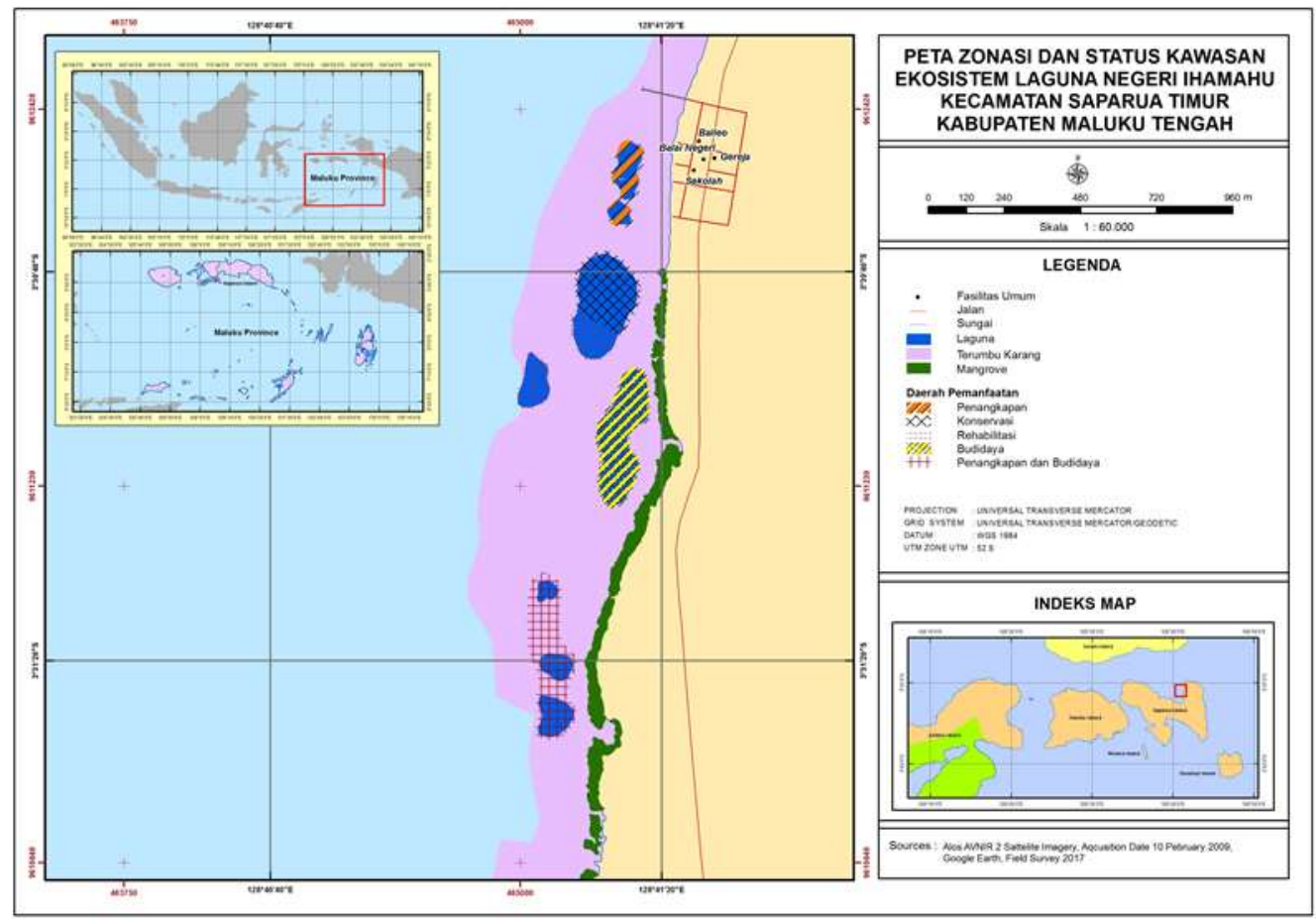

Gambar 3. Zonasi dan status kawasan ekosistem laguna Negeri Ihamahu 
DOI: https://doi.org/10.30598/TRITONvol15issue2page69-75

Tabel 1. Status kawasan dan posisi astronomis ekosistem laguna Negeri Ihamahu

\begin{tabular}{|c|c|c|}
\hline Status Kawasan & Nama Laguna & Posisi Astronomis \\
\hline Kawasan Konservasi & $\begin{array}{l}\text { - Bagian utara Kolam } \\
\text { Basar }\end{array}$ & $\begin{array}{l}3^{\circ} 30^{\prime} 38.00^{\prime \prime} \mathrm{LS}-3^{\circ} 30^{\prime} 44.26^{\prime \prime} \mathrm{LS} \\
128^{\circ} 41^{\prime} 11.31^{\prime \prime} \mathrm{BT}-128^{\circ} 41^{\prime} 17.55^{\prime \prime} \mathrm{BT}\end{array}$ \\
\hline Kawasan Rehabilitasi & $\begin{array}{ll}\text { - } & \text { Bagian selatan } \\
& \text { Kolam Basar } \\
\text { - Kolam Selaono }\end{array}$ & $\begin{array}{l}3^{\circ} 30^{\prime} 44.26^{\prime \prime} \mathrm{LS}-3^{\circ} 30^{\prime} 49.94^{\prime \prime} \mathrm{LS} \\
128^{\circ} 41^{\prime} 11.31^{\prime \prime} \mathrm{BT}-128^{\circ} 41^{\prime} 16.01 " \mathrm{BT} \\
3^{\circ} 30^{\prime} 48.26^{\prime \prime} \mathrm{LS}-3^{\circ} 30^{\prime} 53.95^{\prime \prime} \mathrm{LS} \\
128^{\circ} 41^{\prime} 05.38^{\prime \prime} \mathrm{BT}-128^{\circ} 41^{\prime} 08.61^{\prime \prime} \mathrm{BT}\end{array}$ \\
\hline Kawasan Budidaya & - Kolam Kaki Aer & $\begin{array}{l}3^{\circ} 30^{\prime} 49.73^{\prime \prime} \mathrm{LS}-3^{\circ} 31^{\prime} 04.11^{\prime \prime} \mathrm{LS} \\
128^{\circ} 41^{\prime} 13.20^{\prime \prime} \mathrm{BT}-128^{\circ} 41^{\prime} 18.87^{\prime \prime} \mathrm{BT}\end{array}$ \\
\hline $\begin{array}{l}\text { Kawasan Budidaya dan } \\
\text { Penangkapan }\end{array}$ & $\begin{array}{ll}\text { - } & \text { Kolam Namalono } \\
\text { - } & \text { Kolam Namattiralo } \\
\text { - } & \text { Kolam Hohu } \\
\end{array}$ & $\begin{array}{l}3^{\circ} 31^{\prime} 11.52^{\prime \prime} \mathrm{LS}-3^{\circ} 31^{\prime} 28.46^{\prime \prime} \mathrm{LS} \\
128^{\circ} 41^{\prime} 06.51^{\prime \prime} \mathrm{BT}-128^{\circ} 41^{\prime} 11.33^{\prime \prime} \mathrm{BT}\end{array}$ \\
\hline Kawasan Penangkapan & $\begin{array}{ll}\text { - } & \text { Kolam Kusu-kusu } \\
\text { - } & \text { Kolam Aer salobar } \\
\text { - } & \text { Kolam Ayau }\end{array}$ & $\begin{array}{l}3^{\circ} 30^{\prime} 35.22^{\prime \prime} \mathrm{LS}-3^{\circ} 30^{\prime} 26.66^{\prime \prime} \mathrm{LS} \\
128^{\circ} 41^{\prime} 14.43^{\prime \prime} \mathrm{BT}-128^{\circ} 41^{\prime} 18.29^{\prime \prime} \mathrm{BT}\end{array}$ \\
\hline
\end{tabular}

Sedangkan Kawasan Konservasi di Wilayah Pesisir dan Pulau-Pulau Kecil adalah kawasan pesisir dan pulau-pulau kecil dengan ciri khas tertentu yang dilindungi untuk mewujudkan pengelolaan Wilayah Pesisir dan Pulau-Pulau Kecil secara berkelanjutan. Penetapan kawasan konservasi dimaksudkan agar aktivitas pemanfaatan masyarakat tidak berlangsung pada semua laguna, tetapi perlu ada kawasan sebagai penyedia stok sumberdaya bagi laguna di sekitarnya. Tingginya tingkat pemanfaatan masyarakat dapat menyebabkan degradasi sumberdaya yang nantinya berdampak juga bagi masyarakat tersebut (Mustika, 2017). Hal ini perlu dikendalikan sehingga keberadaan sumberdaya ekosistem laguna sebagai penunjang kehidupan masyarakat dapat tetap lestari.

Beberapa area di sekitar Kolam Basar telah mengalami kerusakan khususnya pada ekosistem terumbu karang. Mengingat pentingnya peranan ekosistem tersebut baik secara ekologi dan ekonomi maka perlu dilakukan proses rehabilitasi. Kawasan rehabilitasi ditetapkan mengingat hasil revitalisasi data terumbu karang memperlihatkan adanya kerusakan. Rehabilitasi dapat mengembalikan kesehatan terumbu karang dan fungsinya (Hesley, et al., 2017). Rehabilitasi terumbu karang juga berdampak positif pada penurunan pemanasan global (Brian, et al., 2009). Rehabilitasi Sumber Daya Pesisir dan Pulau-Pulau Kecil adalah proses pemulihan dan perbaikan kondisi ekosistem atau populasi yang telah rusak walaupun hasilnya berbeda dari kondisi semula (Samad et al., 2013; Yamindago, 2015). Dengan kata lain, penetapan kawasan konservasi dan rehabilitasi di ekosistem laguna Negeri Ihamahu bertujuan khusus untuk melindungi sumberdaya ekosistem tersebut dan tidak diperbolehkan adanya aktivitas lainnya dari masyarakat seperti penangkapan. Untuk itu perlu diikuti dengan penegasan aturan jika hal ini telah diberlakukan, agar masyarakat memahami pentingnya keberlanjutan sumberdaya dan manfaatnya nanti bagi kehidupan masyarakat.

Kawasan budidaya pada ekosistem laguna Negeri Ihamahu dimaksudkan agar dapat memanfaatkan karakteristik ekosistem laguna yang terlindung dan stabil selama pasang surut serta potensi sumberdaya yang dapat dikembangkan sebagai target budidaya seperti teripang, ikan samandar dan siput lola. Kolam Kaki Aer, Kolam Namalono, Kolam Namattiralo dan Kolam Kusu-kusu dapat dimanfaatkan sebagai kawasan budidaya berdasarkan beberapa pengamatan terhadap kualitas air serta terdapat komunitas padang lamun sebagai habitat berbagai biota air. Posisi 
beberapa kolam tersebut berada cukup jauh dari pemukiman penduduk sehingga memungkinkan dilakukannya kegiatan budidaya. Kegiatan budidaya ini bertujuan untuk memelihara dan mengembangbiakan beberapa biota air untuk pemenuhan kebutuhan hidup masyarakat (Andreson, 2017). Sedangkan kawasan penangkapan ditujukan pada laguna yang memiliki sumberdaya potensial. Berdasarkan hasil penelitian, Kolam Kusu-kusu, Aer Salobar dan Ayau memiliki potensi sumberdaya yang cukup baik karena kondisi ekosistem terumbu karang termasuk kategori baik. Aktivitas penangkapan ikan selalu dilakukan di kawasan tersebut umumnya menggunakan pancing. Namun demikian, aktivitas budidaya dan penangkapan sangat tergantung pada kondisi alam (Harvey et al., 2017). Hasil penangkapan tertinggi terjadi pada bulan Februari hingga Oktober, namun memasuki musim barat (November - Januari) hasil tangkapan menurun karena angin dan gelombang (Siahainenia, $d k k$., 2017). Penetapan zonasi dan status kawasan ekosistem laguna Negeri Ihamahu ini perlu menjadi pedoman bagi Pemerintah Negeri maupun masyarakat untuk dapat menjaga serta melestarikan sumberdaya ekosistem laguna Negeri Ihamahu.

\section{KESIMPULAN DAN SARAN}

Berdasarkan uraian dan pembahasan yang telah dijelaskan, maka dapat disimpulkan bahwa kesembilan laguna/kolam yang berada di Negeri Ihamahu dikategorikan dalam kawasan konservasi, rehablitasi, budidaya dan penangkapan.

Adapun saran yang dapat direkomendasikan berdasarkan hasil penelitian ini yaitu perlu adanya perlu kegiatan konservasi dan rehabilitasi sumberdaya serta sistem budidaya yang tepat bagi keberlanjutan sumberdaya ekosistem laguna Negeri Ihamahu.

\section{DAFTAR PUSTAKA}

Anderson, J.L., Asche, F., Garlock, T. and Chu, J. 2017. Aquaculture: Its Role in the Future of Food", World Agricultural Resources and Food Security (Frontiers of Economics and
Globalization), Vol. 17, Emerald Publishing Limited, pp. 159-173. https://doi.org/ 10.1108/S1574-871520170000017011.

Anthony, A, J. Atwood, P. August, C. Byron, S. Cobb, C. Foster, C. Fry, A. Gold, K. Hagos, L. Heffner, D. Q. Kellogg, K. L. Dibble, J. J. Opaluch, C. Oviatt, A. P. Herbert, N. Rohr, L. Smith, T. Smythe, J. Swift, and N. Vinhateiro. 2009. Coastal lagoons and climate change: ecological and social ramifications in U.S. Atlantic and Gulf coast ecosystems. Ecology and Society 14(1): 8. [online] URL: http: //www.ecologyandsociety.org /vol14/iss1 /art8/.

Badan Pusat Statistik. 2018. Kecamatan Saparua Timur Dalam Angka. BPS Kabupaten Maluku Tengah

Brian D. Keller, Daniel F. Gleason, Elizabeth McLeod, Christa M. Woodley, Satie Airamé, Billy D. Causey, Alan M. Friedlander, Rikki Grober-Dunsmore, Johanna E. Johnson, Steven L. Miller, Robert S. Steneck. 2009. Climate Change, Coral Reef Ecosystems, and Management Options for Marine Protected Areas. Environmental Management 44(6): 1069-1088. 10.1007/s00267-009-9346-0.

Harvey, A. C., Y. Tang, V. Wennevik, O. Skaala, K. A. Glover. 2017. Timing is Everything: Fishing-season Placement may Represent the Most Important Angling-Induced Evolutionary Pressure on Atlantic Salmon Populations. Ecology and Evolution. 2017;7:7490-7502. DOI: 10.1002/ece3.3304.

Hesley, D., D. Burdeno, C. Drury, S. Schopmeyer, D. Lirman. 2017. Citizen Science Benefits Coral Reef Restoration Activities. Journal for Nature Conservation 40 (2017) 94-99. DOI: 10.1016/j.jnc.2017.09.001.

Mustika, R. 2017. Dampak Degradasi Lingkungan Pesisir Terhadap Kondisi Ekonomi Nelayan: Studi Kasus Desa Takisung, Desa Kuala Tambangan, Desa Tabanio. Dinamika Maritim 6(1): 28-34.

Newton, A., Icely, J. D., Cristina, S., Brito, A., Cardoso, A. C., Colijn, F., Zaldívar, J. M. 2014. An Overview of Ecological Status, Vulnerability and Future Perspectives of European Large Shallow, Semi-Enclosed Coastal Systems, Lagoons and Transitional Waters. Estuarine, Coastal and Shelf Science, 140,95-122.http://dx.doi.org/10.1016/j.ecss. 2013. 05.023.

Richards, Z. T and M. Beger. 2011. A Quantification of The Standing Stock of Macro-Debris in 
Majuro Lagoon and Its Effect on Hard Coral Communities. Marine Pollution Bulletin 62(8): 1693-1701. https://doi.org/ 10.1016/ j.marpolbul.2011.06.003.

Samad, A., A. N. Bambang, N. Afiati. 2013. Coastal People Activity on Mangrove Forest Rehabilitation in Mahakam Estuary. International Journal of Waste Resources 3(1): 34-39. doi: 10.12777/ijwr.v3.i1.p34.

Siahainenia, L., S. F. Tuhumury, Pr. A. Uneputty, N. Chr. Tuhumury. 2017. Bentuk dan Pola Pemanfaatan Ekosistem Laguna Negeri Ihamahu, Maluku Tengah. TRITON: Jurnal Manajemen Sumberdaya Perairan 13(2): 99104.

Smith, M., Love, D. C., Rochman, C. M., \& Neff, R. A. (2018). Microplastics in Seafood and the Implications for Human Health. Current Environmental Health Reports, 5(3), 375$386 . \quad$ https://doi.org/10.1007/s40572-0180206-z.

\section{P-ISSN 1693-6493 E-ISSN 2656-2758}

Willis, K., C. Maureaud, C. Wilcox, B. D. Hardesty. 2018. How Succesful are Waste Abatement Campaigns and Government Policies at Reducing Plastic Waste into the Marine Environment?. Marine Policy 96(2018): 243$249 . \quad$ https://doi.org/10.1016/j.marpol. 2017.11.037.

Xanthos, D\&T. R. Walker. 2017. International Policies to Reduce Plastic Marine Pollution from Single-use Plastics (Plastic Bags and Microbeads): A Review. Marine Pollution Bulletin 118(2017): 17-26. http://dx.doi.org/10.1016/j.marpolbul.2017.02 .048 .

Yamindago, R.I.A. 2015. Restoring Coastal Ecosystems-A Case Studi Malang and Gresik Regency, Indonesia. J. Coast Conserv. 19 (2015):119-130. DOI 10.1007/s11852-0150373-0. 